\title{
A criminalização do tráfico de mulheres: proteção das mulheres ou reforço da violência de gênero?*
}

\author{
Ela Wiecko V. de Castilho**
}

\begin{abstract}
Resumo
O conteúdo de 23 decisões judiciais proferidas no período de 2004 a 2008, em casos de tráfico de mulheres para a prostituição (art. 231 do Código Penal) é analisado no contexto teórico da Criminologia Crítica feminista com o objetivo de verificar se os juízes avaliam o fato na perspectiva de gênero, de maneira a não reforçar a discriminação e a violência contra as mulheres. A análise revela posições ambíguas entre o respeito à liberdade sexual/dignidade humana e a proteção da moralidade pública, bem como a sobrevitimização das mulheres, o que torna duvidosa a eficácia da aplicação da lei penal na prevenção do tráfico.
\end{abstract}

Palavras-chave: Tráfico de Mulheres, Prostituição, Criminalização, Discurso Judicial, Gênero.

\footnotetext{
* Recebido para publicação em setembro de 2008, aceito em outubro de 2008.

** Doutora em Direito pela Universidade Federal de Santa Catarina, professora adjunta na da Faculdade de Direito, Universidade de Brasília (UNB). wiecko@unb.br
} 
A criminalização do tráfico de mulheres

The Criminalization of Trafficking in Women: Protection of Women or Reinforcement of Gender Violence?

\begin{abstract}
The content of 23 judicial decisions reached between 2004 and 2008 , in cases of trafficking women for prostitution (article 231 of the Penal Code) is analysed in the theoretical context of the Feminist Critical Criminology to verify if the judges evaluate the facts in the gender perspective, so that the discrimination and violence against women is not reinforced. The analysis reveals ambiguous positions between respect for sexual freedom/ human dignity and the protection of public morality, as well the overvictimization of women, which calls into question the effectiveness of the penal law enforcement in the prevention of trafficking.
\end{abstract}

Key Words: Trafficking in Women, Prostitution, Criminalization, Judicial Decision, Gender. 
Ela Wiecko de Castilho

\section{Introdução}

$\mathrm{Na}$ criminalização secundária, isto é, na definição da conduta punível em concreto e de quem é criminoso, tratando-se de tráfico internacional de mulheres, os juízes examinam a prova e sentenciam desde uma perspectiva de gênero? Se a resposta for positiva significa que esses profissionais de direito estão atentos à desigualdade material entre homens e mulheres, estão conscientes de sua causa e, portanto, cuidam para que o processo penal não reforce a vitimização delas ou, em outras palavras, não reproduza a violência de gênero contra as mulheres. Se a resposta for negativa significa que o processo penal reproduz a violência contra as mulheres e não alcança o desiderato da prevenção do crime de tráfico com fim de exploração da prostituição. Para responder a esta indagação foram analisadas 23 decisões (19 de primeiro grau e 4 de segundo grau em ações penais relativas à aplicação do art. 231 do Cód. Penal). A decisão de primeiro grau é proferida por um juiz e sujeita à revisão por um tribunal (colegiado de desembargadores). A análise do mérito da causa para concluir pela condenação ou absolvição é denominada de sentença e a decisão do tribunal de acórdão. Na hipótese, de 2004 a 2008, a maioria das sentenças foi proferida por juízes federais de Araraquara, Curitiba, Campo Grande, Natal, Fortaleza, Salvador, Goiânia, Uberlândia, Manaus, Rio Branco, Rio de Janeiro, São Paulo. Três sentenças foram proferidas por juízes estaduais de Miranda (MS), Ituiutaba (MG) e São João do Triunfo (PR). Em um caso, o juiz federal apreciou também o tráfico interno e mantença de casa de prostituição, tendo em vista a conexão com o tráfico internacional. As sentenças dos juízes estaduais versam sobre tráfico interno e mantença de casa de prostituição. Os acórdãos foram proferidos pelos Tribunais Regionais Federais da $2^{\mathrm{a}}$, e $4^{\mathrm{a}} e$ $5^{\text {a }}$ Região (Rio de Janeiro, Porto Alegre e Recife) e pelo Tribunal de Justiça do Paraná. Os fatos objeto das decisões ocorreram entre 1999 e 2006. O conjunto de sentenças e acórdãos foi compilado pelo Escritório das Nações Unidas contra Drogas e 
A criminalização do tráfico de mulheres

Crime, no Brasil, no âmbito de uma pesquisa internacional de como os diferentes países do mundo vêm enfrentando o tráfico de pessoas.

É um levantamento restrito, correspondendo às respostas dadas a ofícios encaminhados por aquele nos primeiros meses deste ano. Procurei verificar a possibilidade de confirmar conclusões da pesquisa realizada pelo Ministério da Justiça, em 2004, que colheu dados de inquéritos policiais e de ações penais em trâmite na Justiça Federal. A tentativa malogrou, porque não constam das decisões, em número suficiente, os dados necessários à confrontação. O único item em que foi possível fazer a comparação foi o relativo ao sexo dos acusados. A pesquisa do MJ apurou um número maior de homens. Nesta, predominam as mulheres. De 70 pessoas acusadas, 39 são mulheres.

Tendo em vista a pequena amostra, as conclusões são meramente sugestivas. Todavia, reforçam resultados de outras pesquisadoras, a exemplo de Vera Regina Pereira de Andrade (1999).

A maioria das condutas ocorreu antes de 29 de março de 2005, data em que entrou em vigor a Lei $\mathrm{n}^{\circ} 11.106$, que modificou o art. 231 do CP, para estabelecer "pessoa" como sujeito passivo do crime de tráfico internacional para prostituição, e não mais apenas mulher. A alteração, uma entre muitas outras, foi promovida com o fim de retirar do Código tipos penais ou expressões contidas neles que traduziam a discriminação de gênero. Aproveitou-se a ocasião para adequar a lei brasileira ao Protocolo Adicional à Convenção de Palermo, que tem como objeto o tráfico de pessoas, ainda que com especial atenção a mulheres, crianças e adolescentes. Nas discussões sobre o projeto de lei, lembro-me que também serviram de fundamento conclusões de pesquisa nacional, segundo a qual os transgêneros e determinados homens (homossexuais, travestis e outros) sofrem discriminação, exploração e violência sexual (Pesquisa, 2002:39). A alteração no art. 231 ainda incluiu o verbo "intermediar", com vistas a ampliar a aplicação da lei penal, bem como generalizou a 
cominação da pena de multa, antes só prevista para a conduta que visasse lucro. Criou, ademais, um novo tipo penal referente ao tráfico interno. A lei nova, portanto, é mais severa. Em observância ao princípio da Constituição, segundo o qual a lei penal não retroagirá, salvo para beneficiar o réu, os fatos foram analisados à luz da lei anterior, mais benéfica. Isso, no entanto, não prejudica as conclusões da análise do discurso.

As decisões condenatórias fundamentaram-se, conforme o caso, nos arts. 231, caput; $231 \S 1^{\circ}, 2^{\circ}$ e $3^{\circ}, 231-A$ e 229 , bem como nos arts. 14, II (tentativa) e 71 (crime continuado).

A redação atual do art. 231 é a seguinte:

Tráfico internacional de pessoas

Art. 231. Promover, intermediar ou facilitar a entrada, no território nacional, de pessoa que venha a exercer a prostituição ou a saída de pessoa para exercê-la no estrangeiro:

Pena - reclusão, de 3 (três) a 8 (oito) anos, e multa.

$\S 1^{\circ}$. Se ocorre qualquer das hipóteses do $\$ 1^{\circ}$ do art. 227 :

Pena - reclusão, de 4 (quatro) a 10 (dez) anos, e multa.

$\S 2^{\circ}$. Se há emprego de violência, grave ameaça ou fraude, a pena é de reclusão, de 5 (cinco) a 12 (doze) anos, e multa, além da pena correspondente à violência.

Tráfico interno de pessoas

Art. 231-A. Promover, intermediar ou facilitar, no território nacional, o recrutamento, o transporte, a transferência, o alojamento ou o acolhimento da pessoa que venha a exercer a prostituição:

Pena - reclusão, de 3 (três) a 8 (oito) anos, e multa.

Parágrafo único. Aplica-se ao crime de que trata este artigo o disposto nos $\S \S 1^{\circ}$ e $2^{\circ}$ do art. 231 deste Decreto-lei. 
A criminalização do tráfico de mulheres

A redação anterior do art. 231 dispunha:

Tráfico internacional de mulheres

Art. 231. Promover ou facilitar a entrada, no território nacional, de mulher que nele venha a exercer a prostituição, ou a saída de mulher que vá exercê-la no estrangeiro:

Pena - reclusão, de 3 (três) a 8 (oito) anos.

$\S 1^{\circ}$. Se ocorre qualquer das hipóteses do $\$ 1^{\circ}$ do art. 227:

Pena - reclusão, de 4 (quatro) a 10 (dez) anos.

$\S 2^{\circ}$. Se há emprego de violência, grave ameaça ou fraude, a pena é de reclusão, de 5 (cinco) a 12 (doze) anos, além da pena correspondente à violência.

$\$ 3^{\circ}$. Se o crime é cometido com o fim de lucro, aplica-se também a multa.

As hipóteses do $\S 1^{\circ}$ do art. 227 são as de vítima maior de 14 anos e menor de 18, e de agente ascendente, descendente, cônjuge ou companheiro, irmão, tutor ou curador ou pessoa a quem esteja confiada a vítima para fins de educação, de tratamento ou de guarda.

Casa de prostituição

Art. 229. Manter, por conta própria ou de terceiros, casa de prostituição ou lugar destinado a encontros para fim libidinoso, haja, ou não, intuito de lucro ou mediação direta do proprietário ou gerente:

Pena - reclusão, de 2 (dois) a 5 (cinco) anos, e multa.

A Criminologia Crítica e teorias feministas constituem o suporte teórico da análise. Considera-se perspectiva de gênero a compreensão de que a relação entre homens e mulheres é uma relação desigual construída socialmente. O conceito adotado de gênero será objeto de maior explicitação a seguir.

$\mathrm{Na}$ primeira parte será apresentada a perspectiva da criminologia crítica feminista que serve de referência teórica para a análise do second code, presente no discurso judicial, sugerido pelo realce dado a determinados aspectos, palavras utilizadas, etc. 
A seguir serão objeto de destaque os discursos nas sentenças que revelam posições incompatíveis com a perspectiva de gênero.

A parte final ocupar-se-á das conseqüências da criminalização desatenta à perspectiva de gênero, isto é, o reforço da violência contra as mulheres.

\section{Análise criminológica na perspectiva de gênero}

A Criminologia da Reação Social, desenvolvida a partir dos anos 60, rompeu com o paradigma causalista centrado no esclarecimento das causas individuais e sociais do crime. Os aportes das teorias interacionistas, em especial do labelling approach, bem como as evidências da criminalidade do colarinho branco e da cifra oculta da criminalidade, ou seja, do número incalculável de condutas definidas pela lei como crime, que são excluídas do sistema penal mediante vários mecanismos, colocou em foco a seletividade intrínseca do sistema e o caráter mantenedor e reprodutor da estrutura socioeconômica. O tema central dessa criminologia não é a criminalidade como objeto em si, mas o processo de criminalização realizado pelo sistema penal, este, entendido em sentido bastante amplo.

A Criminologia Crítica radicaliza a Criminologia da Reação Social, porque vai além da análise do processo de criminalização realizado pelas diversas instâncias formais e informais do controle social, questionando as estruturas socioculturais e econômicas que condicionam esse controle. Nesse sentido, possibilita a análise do funcionamento do chamado sistema penal na perspectiva da variável de gênero.

Baratta (1999b:45) assinala que

somente uma consistente teoria sociológica do direito penal, como a fornecida pela criminologia crítica, aliada a um uso correto do paradigma de gênero neste contexto, podem permitir a compreensão das "vantagens" e das desvantagens das mulheres, enquanto objeto de controle $e$ de proteção por parte do sistema da justiça criminal. 
A criminalização do tráfico de mulheres

Alessandro Baratta, em entrevista a Martínez (1990a:120), considera Criminologia Crítica todas as expressões contemporâneas de um saber aplicado à questão criminal em que a teoria do labelling approach é utilizada, levando em conta, não somente os processos subjetivos de definição do crime e do criminoso, mas também as estruturas materiais da realidade que condicionam os processos $e$ a espiral que deve ligar a "objetividade" e a "subjetividade" na interpretação dos fenômenos do controle social e de seu significado na reprodução da realidade social em um determinado momento histórico.

É importante aclarar o conceito de second code referido na introdução. O interacionismo simbólico, uma das fontes da Criminologia da Reação Social, ressalta que existem, ao lado das normas sociais gerais, por exemplo, as normas éticas ou as normas jurídicas, "normas ou práticas interpretativas e aplicativas que estão na base de qualquer interação social e determinam o "sentido da estrutura social"" (Baratta, 1999a:88). No campo da lingüística, alguns autores denominam as primeiras de surface rules ou general rules, e as segundas de basic rules. Outros chamam estas de second code, normas não-escritas, que funcionam "no processo de imputação de responsabilidade e de atribuição de etiquetas de criminalidade, ao lado do código oficial" (Id. ib.). Alessandro Baratta prefere chamá-las de metaregras e explica que elas

são seguidas, conscientemente ou não, pelas instâncias oficiais do direito e correspondentes às regras que determinam a definição de desvio e de criminalidade no sentido comum, estão ligadas a leis, mecanismos $e$ estruturas objetivas da sociedade, baseadas sobre relações de poder (e de propriedade) entre grupos e sobre as relações sociais de produção (Id. ib.:105).

Igualmente necessário é esclarecer qual a perspectiva de gênero adotada na análise subseqüente da criminalização operada 
por juízes no tráfico de mulheres para fins de prostituição, consubstanciada nas decisões condenatórias ou absolutórias.

Após um extenso recenseamento da utilização da palavra gênero, Louis (2006:713-726) avalia que seu emprego vulgarizado permitiu e justificou a substituição de outras palavras, como "mulheres", "feminismo" e "patriarcado", bem como obscureceu a função política desempenhada pela introdução desse termo no domínio do pensamento.

Pateman (1993:330) observa que o termo

foi introduzido como uma arma na luta contra o patriarcado. $\mathrm{O}$ argumento patriarcal deixa claro que as mulheres estão naturalmente submetidas aos homens, ou seja, a submissão decorre de sua biologia, de seu sexo. Falar em gênero, em vez de se falar em sexo, indica que a condição das mulheres não está determinada pela natureza, pela biologia ou pelo sexo, mas é resultante de uma invenção social e política.

Neste texto, é resgatada essa idéia de gênero como categoria de análise capaz de evidenciar a subsistência do patriarcado, a dominação masculina, as relações de dominação entre os sexos e a desigualdade material entre homens e mulheres.

É comum a utilização do termo "gênero" como sinônimo de "mulheres". Acredita-se que a simples referência ou preocupação com as mulheres em determinado contexto basta para implementar a perspectiva de gênero. É importante, em qualquer estudo social, tornar visíveis as mulheres, mas isso, por si só, não configura a visão de gênero. A Criminologia Crítica feminista mostra como o sistema penal é sexista, como reproduz a desigualdade entre homens e mulheres, mesmo quando, aparentemente, suas regras estão formalmente destinadas a proteger as mulheres. Segundo Smaus (apud Baratta, 1999b:46), uma das funções latentes do direito penal é a reprodução da escala vertical e da estrutura de gêneros da divisão de trabalho na 
A criminalização do tráfico de mulheres

sociedade moderna, bem como do sistema informal de controle a que estão sujeitas as mulheres na esfera privada.

\section{Análise do discurso judicial na ótica da Criminologia Crítica Feminista}

Firmadas as premissas metodológicas, vejamos o que o discurso das decisões judiciais revela acerca da diferenciação que seus autores fazem das qualidades e dos valores masculinos $e$ femininos. Da leitura das decisões surgem com freqüência algumas idéias:

Idéia de que a prostituição não é trabalho e não exige esforço

[Relata o juiz que] a vítima D. revelou, em seu depoimento policial, que já se prostituía em Uberlândia, esclarecendo também que J. se prostituía na Espanha, juntamente com uma prima de nome R. Assim, quando em visita da ré ao Brasil, esta vislumbrou a possibilidade de levar a vítima para Zaragoza/Espanha e lá se prostituírem. [Após analisar depoimentos conclui que] A acusada J. custeou as despesas de transporte (passagens aéreas) e reserva de hotel para que a vítima $\mathrm{D}$. pudesse viajar para a Espanha/Zaragoza e lá se prostituísse, não se consumando porque foram presas em flagrante no aeroporto de Uberlândia. [Ao fixar a pena consignou que J.] foi motivada pela possibilidade de que sua prima ingressasse na prostituição no exterior, a fim de obter lucro fácil [e que] a vítima contribuiu com a conduta praticada pela ré, pois vislumbrava ir para exterior e lá se prostituir e "ganhar um bom dinheiro" (AP 2004.38.03.009328-4).

[Em outro caso, o mesmo juiz relatou que] a acusada L.A. custeou as despesas de transporte (passagens aéreas) e de documentação de viagem para que as vítimas $\mathrm{R}$. e A. pudessem viajar para a Suíça, fornecendo-lhes suporte na chegada até o destino final onde exerceriam o ofício da prostituição, não se consumando porque foram presas em 
Ela Wiecko de Castilho

flagrante no aeroporto de Uberlândia. [No momento da fixação da pena registrou como uma das circunstâncias para agravar a pena mínima que] foi motivada pela possibilidade de que sua amiga $A$. ingressasse na prostituição no exterior, a fim de obter lucro fácil, [bem como] as vítimas contribuíram com a conduta praticada pela ré, pois vislumbravam que com esta aventura internacional poderiam "ganhar dinheiro e poder ajudar sua família” (sic. fl.15) (AP 2004.38.03.009474-5).

O não reconhecimento da condição de trabalho para o exercício da prostituição constitui obstáculo relevante ao desfrute de direitos e desenvolvimento de potencialidades (Juliano, 2005:82). Afirma a autora que a

fuerte discriminación social referente a la prostitución se apoya em las especificaciones de género imperantes em nuestra sociedad. Se han construído modelos de cómo deben ser los hombres y cómo deben ser lãs mujeres, y esto determina lãs expectativas, los premios y las sanciones (Id. ib.:84).

\section{Idéia de que a prostituição tem como causa a pobreza}

Nos casos antes referidos, essa idéia se manifesta de forma subjacente quando o juiz refere a condição de vida das vítimas:

aliciou a vítima nas suas relações de parentesco (prima), pessoa jovem (24 anos), sem qualificação profissional (faxineira), à procura de uma segurança financeira $e$ profissional (AP 2004.38.03.009328-4); aliciou as vítimas nas suas relações pessoais, pessoas jovens, de baixa instrução, à procura de segurança financeira e iludidas pela possibilidade de melhora na condição de vida, sendo uma delas mãe de duas crianças (AP 2004.38.03.009474-5).

Outras vezes é explicitada. Por exemplo, em processo no qual se apurou uma organização dedicada ao envio de garotas 
A criminalização do tráfico de mulheres

para prostituição na Espanha, o juiz, em alentada sentença, observa que

na verdade, a fome e a miséria convencem qualquer pessoa a praticar o que nunca se imaginou capaz, sendo certo, ainda, que nestas condições, crianças e adolescentes são ainda mais facilmente estimulados a fazerem ou deixar que façam atos sequer inteiramente compreensíveis para elas, seguindo, inadvertidamente, o triste exemplo de outras companheiras de infortúnio. [Entretanto, mais adiante admite que] a pobreza é insuficiente para criar uma legião de prostitutas, mas o fazem as percepções ainda silenciosamente cultivadas em nossa sociedade em relação às mulheres, ou seja, aquelas que estabelecem como única coisa de valor na mulher a sua liberdade sexual que, através de seu corpo, tem se transformado em uma ação vendável. É, pois, a cultura machista ainda vigente em nossa sociedade que partindo da percepção da mulher sem nome, sem família, passado, sem vida e sem vontade, autoriza a prostituição. É nessa cultura invisível que o poder econômico e social cria o silêncio a respeito de quem está sendo explorado, machucado e usado, na penosa constatação de que não se tem a quem recorrer, não se tem a onde ir e na impressão íntima de que não se é nada. Outro conceito típico de nossa condição de classe média é que as prostitutas são sujas e contagiosas, fontes de tudo o que é ruim e errado, pelo que é vista como alguém que merece uma punição que a própria vida lhe oferece e não todo tipo de cuidado ou atenção (AP 2004.51.00.501979-4).

Por sua vez, uma desembargadora assim avalia a conduta de uma acusada por tráfico: "o comportamento dela é sempre voltado a essa questão de menosprezo à situação da mulher na sociedade" (TRF2). Na AP 2003.35.00.015904-9/GO, o juiz anotou serem graves as circunstâncias "com aproveitamento da condição econômica desfavorável, da baixa instrução e da origem humilde da vítima". O juiz federal da AP 2004.61.20.001211-9/Araraquara analisou o 
tráfico de mulheres para Portugal como "procedimento vil e desumano: valer-se da miséria $e$ da pobreza e da pouca oportunidade que esse país oferece a seus próprios nacionais".

Na AP 2004.8100.001979-4 o juiz afirma que,

invariavelmente, o tráfico internacional utiliza a natural esperança a que são submetidas todas as pessoas carentes de emprego e de melhores condições de vida, ou seja, prometem empregos vantajosos com remuneração capaz de sustentar a vítima no exterior e sua família no Brasil. [Em outro trecho, afirma] a maioria das mulheres na prostituição não realizaram uma escolha racional e verdadeiramente livre para entrar em tal atividade, mas simplesmente realizaram uma opção de sobrevivência que, na maioria dos casos, sequer foi uma opção, vez que era a única.

Sob um discurso de proteção está presente o não reconhecimento da capacidade das mulheres de exercer o direito sobre o seu próprio corpo bem como a estigmatização social das prostitutas como forma de estabelecer o papel e o lugar das mulheres na sociedade.

\section{Idéia de que a mulher é um ser fraco}

A idéia foi explicitada na AP 2004.51.00.001979-4 neste trecho:

Ainda existem aqueles que exploram mulheres da mesma forma que tal exploração era realizada quando da edição do Código Penal de 1890, ou seja, ainda existem pessoas que induzem mulheres, quer abusando de sua fraqueza ou miséria, quer constrangendo-as por intimidações ou ameaças a se empregarem no tráfico de prostituição; [e, ainda, neste outro] o fato da mulher, já prostituta ou não, aceitar conscientemente submeter-se à prostituição no exterior não ilide o crime, vez que o consentimento da vítima é irrelevante ante os casos de fraude, engano, abuso de poder ou de uma posição de vulnerabilidade na exploração sexual ou práticas similares à escravatura. 
A criminalização do tráfico de mulheres

Idéia de que a prostituição implica em escravidão

O juiz, ao avaliar a conduta da ré $\mathrm{T}$. que promoveu o tráfico de mulheres para a Espanha, afirmou que ela explorou "a desgraça alheia ao promover e facilitar a ida da vítima D. para um país desconhecido em atividade que, quase sempre, se transforma em escravidão sexual" (AP 2005.35.00.004649-0).

No caso de E.C., condenada como aliciadora, a desembargadora, ao julgar, consignou:

Por tudo que nós conhecemos também dessas mulheres que são mandadas para a Europa, especialmente para a Espanha, pode-se dizer que são escravizadas lá, viram escravas sexuais. São situações muito tristes porque são mulheres que são enganadas, são procuradas no interior do país e levadas para o exterior sob a falsa indicação de que lá vão ter emprego honesto, correto. Elas vão enganadas $e$, quando chegam lá, ficam com o passaporte retido, não têm como sair (AP 2004.5101.502996-0).

Afirmar que a mulher é um ser vulnerável ou estabelecer uma relação necessária entre prostituição e redução à condição análoga a de escravo revela a crença na subalternidade da mulher e não aposta no exercício do seu direito à autonomia.

Idéia de que o exercício da prostituição provoca a degradação moral e familiar

O juiz federal de Araraquara indignou-se com a organização criminosa que "ilude e degrada as mulheres nacionais... idéia errônea e equivocada sobre a mulher brasileira" (AP 2204.20.00.1211-9).

Nas palavras do juiz federal do Ceará,

legalizar a prostituição parece ser uma maneira simples de dizer aos governantes que eles não precisam se preocupar em melhorar as condições das populações, vez que sempre haveria a porta da prostituição, abdicando da 
Ela Wiecko de Castilho

responsabilidade de promover um decente e aceitável emprego (AP 2004.81.00.001979-4).

Idéia de que o lugar de mulher é na família

Essa idéia foi expressa na AP antes referida da seguinte forma: "Além de se combater a pobreza, do incesto e das violências sexuais sofridas na infância que empurram a mulher para fora da família e para as profundezas da prostituição...".

A associação da prostituição com a degradação familiar e da mulher, assim como a crença de que o espaço da mulher é o da família, faz parte da ideologia patriarcal, que procura estigmatizar determinados comportamentos como mecanismo de controle social das mulheres, revelando sexismo e, portanto, violência de gênero no plano simbólico.

\section{A relação entre exploração sexual e machismo}

Curiosamente, ao lado de idéias sexistas, ensaia-se a crítica da cultura machista, apresentada como fator para o tráfico de mulheres. Assim, na antes referida AP 2004.81.00.001979-4, por exemplo, o juiz escreveu:

a pobreza é insuficiente para criar uma legião de prostitutas, mas $\mathrm{o}$ fazem as percepções ainda silenciosamente cultivadas em nossa sociedade em relação às mulheres, ou seja aquelas que estabelecem como única coisa de valor na mulher a sua liberdade sexual que, através de seu corpo, tem se transformado em uma ação vendável. É, pois, a cultura machista...

Algumas decisões problematizam o fenômeno da prostituição e a polêmica acerca da legalização da prostituição. Algumas questionam o bem jurídico protegido pelo art. 231. 
A criminalização do tráfico de mulheres

\section{Prostituição: atividade a ser legalizada?}

Uma das decisões, que examinou uma organização sediada no Ceará, dedicada ao tráfico interno e externo de mulheres para a prostituição, fez alongadas considerações sobre o assunto. Conclui ser inconstitucional a legalização "por identificar a dignidade da pessoa humana como fundamento do nosso Estado Democrático de Direito (art.1 ${ }^{\circ}$, III da Constituição de 1988)" (AP 2004.81.00.001979-4). A seu ver, a mulher prostituta não seria aceita como uma trabalhadora comum, a prostituição clandestina, como forma de burlar a vigilância sanitária ou o pagamento de impostos, não desapareceria, é discriminatório o monitoramento apenas de prostitutas com relação a doenças sexualmente transmissiveis $e$, finalmente, desoneraria os governantes de melhorar as condições de vida.

\section{Exploração da prostituição ou a prostituição: maus costumes} ou ofensa à dignidade humana?

O bem jurídico afetado pela exploração da prostituição $e$ pelo tráfico para a prostituição é percebido de forma diversa pelos juízes. Assim, a ré J. teve sua conduta social avaliada como "em desacordo com os bons costumes" (AP 2004.38.03.009328-4). O mesmo foi dito da r. L.A. (AP 2004.38.03.009474-5). Em caso de competência da Justiça Estadual, o juiz disse ter "o comportamento empregado pelo réu ofendido a moral e os bons costumes das famílias de bem, residentes na pacata São João do Triunfo" (AP 22/2006).

No entanto, ao fixar a pena de um italiano, a quem foi imputada a chefia de organização criminosa transnacional, a conduta social é desqualificada em razão dos antecedentes criminais, mas a conduta objeto do processo, de tráfico interno $e$ externo de mulheres para a prostituição, nas palavras da juíza, atenta "também contra a dignidade da pessoa humana". Afirma ainda que: 
Ela Wiecko de Castilho

as conseqüências extrapenais do ilícito foram graves, na medida em que importaram na degradação moral e familiar das vítimas; que o comportamento das vítimas não contribuiu de forma relevante para a conduta do agente (AP 2005.84.00.010012-2). [Em outro momento, já deixara claro entender que a] tipificação autônoma da conduta definida como tráfico interno de pessoas justifica-se tão-só pela necessidade de se aperfeiçoar a punição, a prevenção e a repressão, ou seja, o combate a esse tipo de infração, que atenta não só contra os bons costumes, mas também contra a dignidade da pessoa humana.

Para a juíza da AP 2003.32.007700-7/AM, as conseqüências dos crimes são de "razoável potencial ofensivo e deletério para a moralidade pública e a liberdade sexual".

Ao reformar decisão do juiz de primeiro grau, que revogara prisão preventiva de uma estrangeira acusada de tráfico de mulheres para Portugal, o Desembargador Federal afirma:

[o] bem jurídico tutelado é a dignidade humana dos trabalhadores sexuais, a liberdade da pessoa, o direito à sexualidade, a honra sexual, protegendo-a, absolutamente contra a exploração sexual (2006.84.00.004412-3).

[Outro juiz refere a] gravidade da ofensa à dignidade da pessoa humana que o tráfico de mulheres elabora [e observa que a prostituição conta] com inegável preconceito, sendo patente a tendência de menosprezo às vítimas por parte das autoridades responsáveis que desconhecem tanto a gravidade das condutas para a dignidade das vítimas quanto mesmo a legislação aplicável, com louváveis exceções (2004.81.00.001979-4).

De modo geral, avalio que nas decisões predomina o entendimento de que a prostituição é uma atividade indecente, contrária aos bons costumes. Isso é perfeitamente adequado ao Código Penal, pois o tráfico de pessoas faz parte do título referente aos "crimes contra os costumes". A invocada ofensa à 
A criminalização do tráfico de mulheres

dignidade humana presente em algumas decisões parece ter apropriado o discurso do Protocolo Adicional à Convenção de Palermo sobre o tráfico de pessoas.

A análise sobre o bem jurídico traz à tona a questão da compatibilidade dos tipos penais em vigor no Brasil com as definições estabelecidas por aquele Protocolo. No que diz respeito ao tráfico para fins de prostituição, a definição legal brasileira é mais restrita, porque desconsidera o consentimento válido. Adequar a nossa lei aos parâmetros de Palermo pode ser uma saída para a perseguição da prostituição, mas também pode ser um reforço para a política antimigratória dos países centrais e a redução da proteção às pessoas que vão para o exterior exercer a prostituição.

Significa descriminalizar o recrutamento de pessoas maiores de 18 anos que, validamente, consentem em exercer a prostituição no exterior. As autoridades policiais brasileiras não irão considerálas como sujeitos passivos de crime de tráfico e, se forem detidas em países estrangeiros, não contarão com a assistência e proteção previstas no art. 6 do Protocolo e com a possibilidade de permanecer no território estrangeiro, temporária ou permanentemente. Em muitos casos, serão consideradas como migrantes contrabandeados. O Protocolo Adicional relativo ao contrabando de migrantes por terra, mar e ar assegura proteção aos migrantes, mas, além de não se referir a eles como "vítimas", estabelece a regra de imediato retorno ao país de origem.

\section{Invisibilidade das vítimas}

Não apenas são reveladoras as coisas ditas. Silêncios $e$ omissões são igualmente reveladores do second code. Nessa ótica, chama a atenção a "posição periférica" (Oliveira, 1999:129) das vítimas, isto é, das mulheres, prostitutas ou não.

As decisões evidenciam a constatação de Ana Sofia de Oliveira (Id. ib.:129): "a vítima, além de não receber qualquer benefício, padece os males da vitimização secundária". Esta, 
também chamada de sobrevitimização, consiste, para Flaviane Barros (2008:71), "não no sofrimento sentido pela vítima (critério subjetivo), mas no desrespeito aos direitos $e$ garantias fundamentais dentro e fora do processo penal (critério objetivo)".

Verifica-se que as vítimas são ouvidas na polícia e em juízo e seus depoimentos servem para comprovar o tráfico. Não há nenhuma menção a medidas em favor das vítimas, como ressarcimento, indenização $e$ assistência social. A não ser quando ameaçadas, hipótese em que é providenciada a proteção. Ou seja, a vítima é vista apenas de uma forma utilitária para o processo penal.

A prevenção é apreciada de forma genérica, distanciada do caso julgado, como fez o juiz na AP 2004.8001.001979-4:

cremos que a única prevenção possível seja a prevenção social, qual seja, a ampliação do acesso à educação e à saúde, aumento do acesso da mulher ao mercado de trabalho, maior controle e vigilância nas regióes de fronteira, com imediato treinamento das autoridades encarregadas da expedição de passaportes para prestarem esclarecimentos em entrevistas pessoais com mulheres suspeitas de futura prostituição. Disseminação, por meio de todas as formas de mídia, de informações que auxiliem a prevenir o tráfico e permita que as pessoas denunciem sua prática, bem como cartilhas informativas distribuídas por ocasião da expedição de passaportes ou mesmo impressão de como realizar tais denúncias nos próprios documentos de viagem e/ou passaportes são outras medidas simples de prevenção.

Em muitas sentenças, as pessoas são condenadas a penas restritivas de direito, em geral duas, uma de prestação pecuniária e outra de prestação de serviços à comunidade. A prestação pecuniária consiste no pagamento de um montante em dinheiro que pode ser deduzido de eventual indenização civil. Em nenhum caso a prestação pecuniária foi direcionada na sentença para as 
A criminalização do tráfico de mulheres

vítimas ou para entidades sociais que tem como finalidade apoio às vítimas de exploração sexual. A prestação de serviços a comunidade também é genericamente imposta para ser cumprida em entidades sociais. É bem verdade que o juiz da execução da pena pode suprir a omissão no que diz respeito ao tipo da entidade onde em favor da qual deve ser cumpridos serviços ou a prestação pecuniária, mas, de qualquer forma, a omissão nas sentenças é relevante.

De modo geral, mesmo nos casos em que as vítimas se declararam prostitutas ou que, não sendo, sabiam que iriam exercer a prostituição, os juízes não consideram essa circunstância na aplicação da pena-base. Em mais de um caso, o juiz federal de Goiânia não valorou o comportamento das vítimas, pois "não foi determinante para a prática criminosa, porque se não fossem essas vítimas poderiam ter sido outras a ser enviadas ao exterior" (AP 2005.35.00.006120-4/GO e 2006.35.00.017146-5/GO). Entretanto, em um caso de tráfico internacional para a Espanha (AP 2006.33.00.005669-9), o juiz considerou que "o comportamento das vítimas facilitou a ação do agente, já que anuíram no transporte a esta Capital, para posterior deslocamento para a Europa". Na AP 1999.70.00.028853-4/PR, o juiz avaliou que "as vítimas contribuíram para a prática do crime, aceitando de livre e espontânea vontade a proposta para trabalharem como prostitutas no exterior". Também nas AP 2004.38.03.009328-4 e 2004.38.03.009474-5, o juiz avaliou, respectivamente, que:

A vítima contribuiu com a conduta praticada pela ré, pois vislumbrava ir para exterior e lá se prostituir e "ganhar um bom dinheiro"; As vítimas contribuíram com a conduta praticada pela ré, pois vislumbravam que com esta aventura internacional poderiam "ganhar dinheiro e poder ajudar sua família". 
Ela Wiecko de Castilho

Na AP 2000.35.00.0010684-3-GO, o juiz entendeu não dever

aquilatar o comportamento da vítima, uma vez que o objeto jurídico do delito em análise é a moralidade pública, em especial por haver, na hipótese, conhecimento por parte das mulheres aliciadas que elas se destinavam ao meretrício no estrangeiro.

\section{Conclusão}

A análise das decisões judiciais revela a subsistência da concepção da mulher como sexo frágil, e do seu papel tradicional no contexto familiar. É inadmissível nessa concepção que a mulher exerça a prostituição por livre e espontânea vontade. Mas, ao mesmo tempo, não há grande preocupação com essa mulher que se viu compelida a prostituir-se. Seu comportamento, inclusive, serve para reprovar com menos rigor a conduta da pessoa acusada. Constata-se no discurso judicial a observação de Dolores Juiano (2005) de que o trabalho sexual, embora não constitua crime, produz a mesma estigmatização reservada para os criminosos. De certa forma, é uma criminalização sem tipo penal, sem processo legal. $\mathrm{O}$ juiz, ao aplicar a sentença penal, confirma a idéia socialmente construída de que mulheres pobres e pouco instruídas servem ao mercado do sexo que a solução do problema consiste na melhoria das condições de educação, emprego e saúde. Os homens $e$ as mulheres que as aliciam têm sido condenados, em geral com muito rigor, mas isto não promove o decréscimo do recrutamento de mulheres ou da atividade da prostituição, como se pode perceber das próprias decisões, quando transcrevem depoimentos das mulheres recrutadas. Confirma-se a hipótese de Andrade (1999:113), de que o sistema penal é ineficaz para proteger as mulheres, porque

não previne novas violências, não escuta os distintos interesses das vítimas, não contribui para a compreensão da 
A criminalização do tráfico de mulheres

própria violência sexual $e$ a gestão do conflito $e$, muito menos, para a transformação das relações de gênero.

A análise das decisões judiciais ressalta, de um lado, a centralidade do tema da prostituição $e$, de outro, a ambigüidade decorrente da não criminalização de quem exerce a prostituição, mas de criminalizar quem a promove ou facilita. Uma questão que fica em aberto é saber se a discriminação de gênero, presente na criminalização do tráfico de mulheres, reduzir-se-á, caso a lei seja alterada conforme os conceitos estabelecidos no Protocolo Adicional de Palermo sobre o tráfico de pessoas.

\section{Referências bibliográficas}

ANDRADE, Vera Regina Pereira de. Criminologia e feminismo: da mulher como vítima à mulher como sujeito de construção da cidadania. In: CAMPOS, Carmen Hein de. Criminologia e feminismo. Porto Alegre, Sulina, 1999, pp.105-117.

BARATTA, Alessandro. Criminologia crítica e crítica do direito penal: introdução à sociologia do direito penal. 2.ed. Rio de Janeiro, Freitas Bastos,1999a [Trad.: Juarez Cirino dos Santos].

O paradigma de gênero: da questão criminal à questão humana. In: CAMPOS, Carmen Hein de. Criminologia e feminismo. Porto Alegre, Sulina, 1999b, pp.19-80.

BARROS, Flaviane de Magalhães. A participação da vítima no processo penal. Rio de Janeiro, Lumen Juris, 2008.

COLARES, Marcos. Diagnóstico sobre o tráfico de seres humanos: São Paulo, Rio de Janeiro, Goiás e Ceará. Brasília, Secretaria Nacional de Justiça, 2004.

JULIANO, Dolores. El trabajo sexual em La mira. Polêmicas y estereótipos. Cadernos Pagu (25), Campinas-SP, Núcleo de Estudos de Gênero - Pagu/Unicamp, jul./dez. 2005, pp.80-88.

LEAL, Maria Lúcia e LEAL, Maria de Fátima. (orgs.) Pesquisa sobre tráfico de mulheres, crianças e adolescentes para fins de exploração sexual comercial no Brasil-PESTRAF: relatório nacional. Brasilia, CECRIA, 2002. 
Ela Wiecko de Castilho

LouIS, Marie-Victoire. Diga-me, o que significa gênero? Sociedade e Estado, vol.1, $\mathrm{n}^{\circ}$ 3, Departamento de Sociologia da Universidade de Brasilia, set./dez. 2006, pp.713-726.

MARTÍNEZ SÁNCHES, Mauricio. Qué pasa en la criminologia moderna?. Bogotá, Temis, 1999.

OliveIRA, Ana Sofia Schmidt de. A vítima e o direito penal. São Paulo, RT, 1999.

Pateman, Carole. O contrato sexual. São Paulo, Paz e Terra, 1993 [1988] [Trad.: Marta Avancini]. 